\title{
INSECURITAS VACUI. OPASNOSTI OD ZAPUŠTENIH GRADSKIH PROSTORA
}

\author{
Aleksandar V. Gordić ${ }^{1}$ \\ $\mathrm{UDK}=351.778 .52$ \\ https://doi.org/10.18485/fb_ubur.2018.1.ch9 \\ ${ }^{1}$ Fakultet za primenjenu ekologiju Futura, Beograd, \\ algordic@gmail.com
}

\section{Sažetak}

Ostavljajući po strani nacionalnobezbednosne aspekte ogromnih praznih teritorija u ruralnim oblastima, koji u poslednje vreme postaju sve izraženiji, rad će se usredsrediti na opasnosti koje vrebaju od zapuštenih ili napuštenih urbanih mikrolokacija. One, kao mesta ruševnih objekata i staništa insekata i glodara, ali i istorijskih zagađenja zemljišta i vazduha (deponije građevinskog, industrijskog i komunalnog otpada) predstavljaju ne samo fizičkotehničku i ekološku pretnju za okruženje, nego, kao stecište raznih marginalnih/devijantnih grupa, ujedno potencijalno izvorište (širenja) kriminaliteta i socijalne patologije. Drugim rečima, razjašnjavaće se kako fizičkoekološki, tako i socijalnoekološki elementi urbanog propadanja. Pre svega će se osvetliti uzroci nastanka ovakvih lokacija, odnosno njihovog napuštanja ili zapuštanja, koji ne leže isključivo u ekonomskoj sferi, nego se tiču i celokupnog arhitektonsko-urbanističkog i društvenog okruženja, pa je i za sanaciju ili regulaciju ovakvih (ne)mesta potrebno preduzimati sveobuhvatne mere na raznim nivoima delovanja. Premda će se rasmatrati i vrlo aktuelna tematika braunfilda kao nasleđa modernosti i tekovine globalnog preseljavanja industrijskih i drugih sadržaja (ne ulazeći u njihovu podrobnu klasifikaciju), naglasak će se staviti na uže lokacije (neizgrađene građevinske parcele, nedovršene ili privremeno napuštene objekte, nedovoljno posećivane uglove javnih površina). Dakle, to su mikrozone koje su manjkom brige ili socijalnog nadzora obeležene kao potencijalna žarišta budućih problema (tzv. sindrom razbijenog prozora), bilo da je reč o privatnim ili javnim prostorima (odnosno nekom prelaznom obliku). Premda ovakve lokacije postoje i u seoskim naseljima, tamo ne predstavljaju toliku opasnost, jer nema kongestije (gustina stanovništva je [sve] manja), a i stepen društvene kontrole viši. Pri predlaganju modela regeneracije zapuštenih područja poći će se od odgovornosti vlasnika/titulara imovine, lokalne zajednice/samouprave i društva/države u celini, uz jasno definisanje dužnosti svih aktera/stejkholdera (i institucionalno nametanje uslovâ korišćenja). To bi podrazumevalo oročeno obavezno, prinudno privođenje nameni (i to poželjno višestrukoj, jer je monofunkcionalnost sama po sebi negativni potencijal za stvaranje praznog prostora ili negativnih niša) i podsticanje što potpunijeg i raznovrsnijeg korišćenja svakog delića gradskog prostora, kao retkog, ali i rizičnog resursa. Pri tom se neće uzimati u obzir jedino kratkoročni, usko ekonomski aspekti (što se često čini u publikacijama posvećenim braunfildima), nego vizija održivog razvoja na makronivou, koja destimuliše orijentisanje na ekspanziju/invaziju ka grinfildima na gradskim obodima. Radi obezbeđivanja prediktivnosti (u svrhu prevencije i blagovremenog reagovanja), naznačiće se indikatori propadanja/zapuštanja, 
čije vrednosti treba da služe kao signali upozorenja, kada su i troškovi revitalizacije niži, a društvena vrednost ili upotrebljivost prostora veća.

Ključne reči: zapuštene lokacije, braunfild, urbana ekologija, sanacija, revitalizacija, lokalna zajednica

\section{Uvod}

Najpre, treba pružiti kratko objašnjenje samog naslova: horror vacui (strah od praznine) označava starostavni metafizički/ontološki, prirodoslovni/fizički i aksiološki princip, koji se može protegnuti na bezmalo sva područja ljudskog života, a takvim strahom su tumačene mnoge fizičke pojave, kao što je vazdušni pritisak. Analogija se sastoji u tome da, kao što, navodno, priroda ne dopušta potpuno prazan prostor (vakuum), tako se i na društvenom nivou pojavljuje bojazan od boravka u praznom, zapuštenom prostoru, lišenom namene. Takve površine onda očekivano postaju žarišta raznih negativnih fenomena, pre svega komunalnih i ekoloških, ali i sociopsiholoških, a suvišno je i pominjati da takvo zemljište postaje odbojno za investitore, pa mu samim tim opada ekonomska vrednost. Nebezbednost (insecuritas) takvih oblasti sasvim je očigledna, a u ovom radu će se nastojati da se pokaže kako se pitanja bezbednosti i sigurnosti ne mogu obrađivati izolovano od svih aspekata zapuštanja/opustošenosti i bez interdisciplinarnog uočavanja povezanosti neželjenih tokova na raznim nivoima.

Zapuštena područja su značajna mikro-, ali i makrourbanistička tema, jer se ne tiču samo komunalnohigijenskih i sanitarnih problema, nego i celokupne strategije održivog (fizičkog, ekonomskog i socijalnog) razvoja, odnosno upravljanja prirodnim i stvorenim resursima, uključujući ekološku i socijalnopsihološku ravan. U seoskim naseljima degradirane zone nisu toliko česte, pa samim tim ne predstavljaju krupan problem (pošto po pravilu ne mogu ni da privuku nepoželjne stanovnike, životinjske ili ljudske), ali su u gradu devastirane površine i objekti upravo kritična područja i hroničan problem, jer koncentracija aktivnosti i sadržaja u urbanim celinama podrazumeva povlačenje ekoloških i socijalnih negativnosti na ispražnjene, napuštene parcele, koje su pod slabijim formalnim i neformalnim nadzorom. Doduše, u širokim ruralnim oblastima Srbije poslednjih decenija nastupa proces dezertifikacije, zakorovljavanja i oprašumljavanja, uzrokovan dramatičnom depopulacijom čitavih regiona, međutim, ta nevolja se mora rešavati sistemskim merama demografske politike i uređivanja celokupne vangradske teritorije.

Devastacija pojedinih gradskih parcela i kvartova, osim toga što je posledica gubljenja prvobitne namene (prvenstveno industrijske posle neuspele tranzicije, ali i infrastrukturne, stambene, komercijalne, pa i sportsko-rekreativne), ujedno čini i naličje kongestije, preteranog zbijanja na pojedinim tačkama centralizacije aktivnosti - može se s podosta pouzdanja tvrditi da je hiperkoncentracija (koliko na transnacionalnoj, toliko i na nacionalnoj ravni, ali i na mikronivou) jedno od bitnih obeležja globalizacije, međutim, prvi njeni nagoveštaji ukazuju se već sredinom 
minulog veka, a nijedno ne-totalitarno društvo, koje ne koristi mehanizme administrativnih mera i državne represije, nije uspelo da izađe na kraj s ovom ,prirodnom" tendencijom, motivisano uglavnom usko shvaćenim ekonomskim razlozima, koji osujećuju održivi razvoj. U Srbiji je ovaj problem zaoštren već gotovo poluvekovnom proliferacijom (polu)divljih, tj. urbanistički i komunalno neuređenih naselja na prilazima čak i manjih, gotovo svih varoši i opštinskih mesta (pa i onih koja su sama zahvaćena iseljavanjem), daleko od velikih konurbacija, pa se može reći da bezmalo polovinu naše zemlje čine ovakve nelegalne naseobine, koje su produktivna podloga za nastajanje „braunfilda“ i, uopšte, opustošenih staništa. Tome nisu pogodovali samo stihijska (para)urbanizacija i (u poslednjih četvrt veka) masovni talasi izbeglica i drugih doseljenika, nego pre svega odsustvo odgovarajuće, realistične strategije održivog prostornog, ekonomskog i društvenog razvoja.

\section{Pokušaj tipologije}

Vrlo je teško pružiti neku iscrpnu i jednoznačnu klasifikaciju zapuštenih, zapustelih objekata i područja, pošto gubljenje nekadašnje namene po pravilu izaziva i odlazak drugih aktivnosti osim osnovne - odnosno, iz propadanja jedne funkcije (npr. industrijske) redovno proističe i umanjivanje ili nestanak drugih (recimo, stambene, komercijalne itsl). Deterioracija (urban blight) na jednom nivou obično vodi i slabljenju svih ostalih komponenti prostora, pri čemu su uzročno-funkcionalne relacije najčešće dvosmerne - npr. komunalno zagađenje predisponiše propadanje infrastrukture, što sa svoje strane vodi daljem zagađenju (ili makar umanjivanju kapaciteta za sanaciju ili otklanjanje nehigijene); kao što i depopulacija snižava ekonomsku vrednost određenog kvarta, a ona, opet, uzrokuje manjak brige za ekološke i socijalne elemente; itsl.

Provizornu tipologiju ispražnjenih, zapustelih gradskih prostora svakako bi trebalo započeti od industrijskog brownfield-a, najzastupljenijeg ne samo u našoj sredini, nego i u svim istočnoevropskim zemljama, pa i na (do pre nekoliko decenija) industrijski orijentisanom Zapadu, te o njima ovde neće biti mnogo reči, jer su teorijski razrađeni brojni vidovi njihove sanacije, remedijacije i revitalizacije. Međutim, tu su i stambeni (nedovršeni i napušteni objekti), pri čemu naročito treba ukazati na brojne neiskorišćene vikend-zone, možda najveću promašenu investiciju epohe tzv. realnog socijalizma. Vikendice su (uz gastarbajterske kuće u brojnim zabačenim selima) možda ne samo najozbiljniji urbanistički propust ranijeg društvenog uređenja i primer u svakom pogledu narušenih predeonih vrednosti, nego verovatno i najneizlečiviji braunfild, teži od divljih prigradskih naselja, pošto ih mlađi naraštaji sve manje koriste, dok u njima uglavnom borave jedino nevoljnici koji nemaju nikakav drugi smeštaj (npr. izbeglice, odnosno interno raseljena lica, za koje je to bio jedan od načina zbrinjavanja kao mere zaštite); no, kada se pripadnici tih osiromašenih slojeva, snagom biološke nužnosti, prorede, ovi delovi teritorije, koji zapremaju desetine, pa i stotine kvadratnih kilometara u blizini većih gradova, postaće sveobuhvatna pustinja, nepogodna za korišćenje u poljoprivredne ili neke druge svrhe. 
Zatim slede saobraćajna infrastruktura, uključujući skladišta, hangare, zastarela saobraćajna čvorišta (objekte i uređaje), ali i poslovni objekti, pogotovo tržni centri, kojima je u ovdašnjim okolnostima vek trajanja prilično kratak, pa danas mnogi od lokala u njima čame uglavnom napušteni od negdašnjih zakupaca ili vlasnika (Čumićevo sokače, „Staklenac“, „Sunce“ i zanatski centri u savskim blokovima, pa donekle i ,Stari Merkator“, ali i opusteli zanatsko-tržni kompleksi u središtima mnogih novobeogradskih i drugih prestoničkih naselja; takvih primera ima i u manjim mestima Srbije (kao što je, na primer, tržni centar „Kalča“ u Nišu). Najzad, tu su i rekreativne površine koje su izgubile privlačnost za okolno stanovništvo ili nedovršeni, već umnogome ruinisani objekti koji verovatno nikada neće biti stavljeni u funkciju (poput nesuđenog novobeogradskog akva-parka ili sada već i srušenog zabavnog parka na Banjici). Bez obzira na to u koju specifičnu vrstu spadaju, sve takve zone ili građevine doživljavaju sličnu sudbinu, nezavisno od imovinskopravnih odnosa, blizine stambenih ili poslovnih zona, kao i raznih drugih obeležja: postaju ne samo izvorište komunalne nehigijene i ekološka opasnost za okolinu, nego i stecište sociopatogenih pojedinaca i grupa, a obično utiču i na snižavanje ekonomske valorizacije susednih kvartova.

Kada se sistematski rasmotri simptomatologija zapuštenih prostora, čini se da bi u njih valjalo uključiti i sve objekte koji se nedovoljno koriste ili su izgubili prvobitnu namenu (pa čak i takve koji su tokom većeg dela dana i naročito noći sasvim pusti, kao što su stadioni, prigradski parkovi, garaže, parkinzi, groblja, ali, recimo, i mnogi bolnički i verski kompleksi u noćnim satima, podzemni prolazi, jer su sve to potencijalno nebezbedne zone, najčešće bez ikakvog efektivnog nadzora). U ovu, širu kategoriju vrlo često spadaju i (kako gradska, tako sve više i seoska) školska dvorišta, koja, zavisno od brige lokalne zajednice, mogu figurisati i kao potencijalno nebezbedni, ali i kao vrlo bezbedni prostori (lokusi sigurnosti). U selima su školski prostori po pravilu bezbedniji (jer su u centru/sredselu, pa su osobena žarišta okupljanja meštana, ali predmet posebne pažnje u pogledu uređivanja). Dakle, zapuštene prostore ne moraju obeležavati drastično zagađenje ili nagomilavanje otpada (što je tipično za industrijske braunfilde, koji se uglavnom dovode u vezu sa ekološkim kriminalom), ruševine i slične ekstremne situacije dovoljno je da je reč o neprijatnim prostorima s ograničenim vremenskim korišćenjem: neobezbeđena gradilišta, nedovršeni objekti, zapuštene parcele, privremeno ili stalno napušteni objekti, groblja, stadioni, zanemarena igrališta za decu, skloništa koja nemaju vlasnika (kojima niko ne gazduje), pristaništa i slični objekti s nepotpunim intervalom upotrebe, odlagališta raznovrsnog materijala itsl.

Objektivno utemeljen ili ne, osećaj nelagode iskrsava uvek pri prolasku pored retko korišćenih ili zapuštenih parcela, čak i kada ona ne predstavljaju fizičku, biološku ili tehničku pretnju; tako su priobalne ili lučne privredne zone, u kojima se noću ne odvijaju nikakve druge aktivnosti, ,idealno“ mesto za generisanje požarâ (i drugde: Grčka, Rusija) i drugih incidenata, a velike luke su u većini svetskih gradova lokacije čiji se noćni obilazak izbegava. Tako, na primer, nije bitna samo objektivna, zvanično registrovana stopa kriminaliteta, nego i subjektivni osećaj (ne)prijatnosti, odbojnosti, što onda dodatno utiče na izbegavanje, napušta- 
nje i, posledično (usled nebrige), dalje propadanje lokacije - za urbanizam je unekoliko važnija bojazan od kriminala nego sâm kriminal, tj. njegova službeno utvrđena stopa. Stoga se mora imati na umu kako objektivna tako i subjektivna ravan strahova, tj. sveukupna ljudska bezbednost (ne samo fizička, nego i psihološka, ekološka, pa i ekonomska, kad je reč o imovini). Strah ne mora biti izazvan isključivo fizičkim opasnostima niti biti egzistencijalne prirode, od zločina: za nelagodnost je dovoljna nepreglednost i odsustvo nadzora, što vodi difuznoj socijalnoj patologiji, koja ne mora biti prekršaj zakonskih, nego tek običajnih normi, pa je bitno suziti mogućnosti ne samo za najteže oblike kriminaliteta, nego i za druge nepoželjne pojave (kockanje, narkomanija, prostitucija, što sve doprinosi nesigurnosti). U slabo frekventizovanim četvrtima nastupa i tipično urbani kriminalitet, koji (na osnovu raznih opažljivih osobina lokacije) valja i predviđati i osujećivati (različite stope u pojedinim krajevima nisu uslovljene niti objašnjive isključivo ekonomskim činiocima).

Sve u svemu, čak i kada osnovna namena izvesne površine nije nepovratno izgubljena, monofunkcionalnost (nastala usled modernističke preokupacije striktnim zoningom) i nepotpuna (vremenska) upotreba same po sebi indukuju koliko objektivnu nebezbednost, još i više subjektivni osećaj nesigurnosti. Zbog toga ne moraju biti na delu striktna sekuritizacija i merljive pretnje, nego naprosto nelagodnost ili odbojnost pri pogledu ili prolaženju pored zapuštenih prostora. Za urgentnu remedijaciju, svakako, prioritetne su ,crne“ i ,mrke“, ali ništa manje nisu važne $i$ „bele“ ili „sive“ mrlje (tzv. grejfildi), (polu)prazni prostori, na putu propadanja, koji ne privlače stanovnike i samim tim postaju jezgra generisanja neželjenih pojava.

Još jednom treba naglasiti da, iako je harakteristično svojstvo zapuštenih područja veliki „ekološki otisak/trag“ (kako fizičko-, tako i socijalnoekološki), tj. opterećenje raznim oblicima zagađenja (pa i onim novima, kao što su buka, svetlost ili razni vidovi zračenja), on ne mora biti presudan, dok je (i za bezbednosne, ali i za ekonomske, urbanističke i socio-psihološke aspekte) neuporedivo važnija redovna posećenost i aktivno korišćenje, što jedino može navoditi na adekvatno uređivanje i funkcionalno održavanje konkretnog lokaliteta. Svaka suboptimalnost, odnosno deficit $u$ iskorišćavanju izvesne površine umanjuje (ne jedino ekonomsku, nego i opštu upotrebnu) vrednost i atraktivnost određenog mesta, a kada nastupe prvi znaci propadanja, oni imaju tendenciju da efekte spiralno, mehanizmom pozitivne (tj. nepoželjne, uneravnotežavajuće) povratne sprege prošire na sve nivoe organizacije prostora. Nije dovoljna tek sanitarna remedijacija, bitnija je efikasnost u pogledu mesta, vremena i urbanističko-arhitektonskih rešenja nego fizičko uklanjanje ili čišćenje zapuštenih objekata i površina. Otuda se pomenuti elementi ne smeju posmatrati i obrađivati izolovano, niti primenjivati universalni recepti za svaku zapuštenu zonu, nego se mora pristupati kompleksno i s obzirom na osobenosti svake pojedinačne urbanističke celine. 


\section{Uzroci i fenomenologija zapuštanja}

Za regulisanje zapuštenih područja, podložnih propadanju, tj. eskalaciji deteriorizovanja, daleko je bitnije identifikovanje uzrokâ (ili makar blagovremeno ustanovljavanje simptomâ) nego sprečavanje ili umanjivanje posledica. Iako je etiologija zapuštanja veoma heterogena, valja napomenuti da ekološki, ekonomski i bezbednosni rizici ne rastu samo s proređivanjem nego i s povećanjem gustine stanovništva i koncentracije aktivnosti, pošto hiperkoncentracija (kao što je notorno još od Čikaške škole i socijalne psihologije s početka proteklog veka) sama po sebi izaziva napetost, dok, sa druge strane, izaziva napuštanje zona koje same po sebi (u fizičkogeografskom smislu) nisu nepovoljne za mnoge ljudske aktivnosti. Fizički i socijalni pritisak na preostali prazan prostor veći je u gusto nastanjenim zonama nego $\mathrm{u}$ područjima koja su ravnomerno popunjena raznim funkcijama i sadržajima.

Stoga je potrebno razviti što obuhvatniju mrežu indikatorâ propadanja na fizičkom, ekološkom, ekonomskom i socijalnom nivou, koja bi obuhvatila kako „tvrde“ podatke (o zagađenju, kriminalitetu, opadanju tržišne vrednosti, kao što je ukazao profesor Vilbert Rodenhojs), tako i one „meke“, koji bi uključili „sivu zonu“" neregistrovanih prestupa i anomalija - jedino je tako izvodivo (premda teško i nezahvalno) predvideti srednjo- i dugoročnu sudbinu pojedinih prostora, što onda omogućuje strateško planiranje, naspram sanacionog i palijativnog ,gašenja požara“, odnosno remedijacije crnih tačaka (što ne samo da redovno iziskuje veće troškove, nego obično ne dovodi do restitutio/restauratio integra, potpunog oporavka). U načelu je podesnije zapuštena područja definisati što šire, pošto inferiornost u pogledu ma kojeg indikatora upućuje na potrebu preduzimanja prikladnih mera na raznim nivoima: fizički, ekološki, ekonomski itd. pokazatelji uvek imaju (osim indikativnog, deskriptivnog) i direktivni smisao, tj. (ne)posredno upućuju na korake koje valja preduzeti na sanaciji i, što je još važnije, svakovrsnom poboljšavanju i unapređivanju zatečenog stanja, pre nego što poprimi neumitno negativan tok.

Kad se govori o samim indikatorima, ovde se ne pretenduje da se ponudi sveobuhvatna mreža, koja bi zahvatila sve zamislive vidove umanjivanja urbanističke, ekološke, ekonomske, pa i estetske i pejzažne vrednosti prostora, ali se, na osnovu raznih dosadašnjih pokušaja, mogu preliminarno nabrojati sledeći: broj i vrsta funkcija, ekonomska vrednost po jedinici površine, ekološko-higijenski parametri, socijalni, kao što su stalna naseljenost i frekventna posećenost; zauzvrat je potrebna ravnoteža ispunjenosti u prostornom i vremenskom smislu, ispunjenost sadržajima tokom celog dana i godine, koji su višestruko međupovezani. Tako se, recimo, posećenost ne odnosi isključivo na kvantitet, pa ni na interval (npr. celodnevno/-noćno prisustvo zainteresovanih aktera), nego, osim dnevnog, dotiče i dugoročnu, perspektivnu dimenziju: npr. jedan od glavnih uzroka propadanja (blight-a) centralnih gradskih četvrti demografskog je haraktera, tj. proizašao je iz senilizacije jezgara ne samo evropskih gradova. Opet, kad je reč o bezbednosnim činiocima, bitna je i rezilijentnost (otpornost na izazove) u normalnim uslovima (ne samo prema drastičnim hazardima i rizicima, nego i u odnosu na manje poremećaje, npr. infrastrukturnim, što uključuje i ekonomsku dimenziju). 
Kao što je umesno istakao profesor Bo Grenlund, posebno su značajni kvalitativni, ne sasvim merljivi, ,meki“ parametri, kao što je nalaženje/figurisanje na odgovarajućim linijama kretanja, ili koridorima (gustina tokova motornog, ali pre svega pešačkog saobraćaja), i blizina punktova (ključnih orijentira - Linč). Glavni pokazatelj napuštanja/zapuštanja jeste proređivanje korišćenja određenog koridora ili površine u skladu s namenom/namerom, na šta utiču preglednost/transparentnost prostora, atraktivnost, multifunkcionalnost, simbolička pertinentnost jednom rečju, ispunjenost ili oplemenjenost prostora raznovrsnim sadržajima, od snabdevenosti pogodnom infrastrukturom do bogatstva kulturalnih i istorijskih znamenitosti (i upućivanja/referenci na njih). Presudno je da što veća prostorno-vremenska pristupačnost, frekventna posećenost pruža visok stepen socijalne kontrole teritorije (a neformalan društveni nadzor uvek je uspešniji od FTO [osoblja, fizičkih prepreka, tehničkih oruđa, nalik kamerama] i zapravo je glavni mehanizam deterencije/odvraćanja - nisu dovoljne urbanističke i čisto bezbednosne mere, poput osvetljenja, nego sigurnost daju, uz frekventne posete i neformalni nadzor, prvenstveno briga i staranje lokalne zajednice o svim delićima/uglovima površine); u vezi s ovim vredi uputiti na sindrom „razbijenog prozora“ (primetne, upadljive nebrige o fizičkim i simboličkim tekovinama) i vaninstitucionalno održavanje javnog reda, koje se manifestuje u socijalnim poduhvatima, ali i sankcijama za patogeno ponašanje.

Zato je teško prenaglasiti značaj identifikacije (i stanovnikâ, ali i prolaznikâ) s prostorom i njegovim sadržajima (uključujući svaki zabačeni ugao), kao i važnost osećaja pripadnosti, što vodi strožoj i redovnijoj neformalnoj kontroli. Bitna je identifikacija sa svakim segmentom prostora, delovanje na njegovom održavanju i unapređivanje - napuštene parcele neminovno nastanjuju (za lokalnu zajednicu najčešće nepoželjni, a u najmanju ruku nenameravani) korisnici ili inhabitanti, koji, makar subjektivno, mogu da indukuju neprijatnost. Na primer, skvoteri u divljim/neplanskim naseobinama, kerovo[d]ci i drugi uzgajivači životinja, neformalne grupe (ponekad i alternativne, umetničke ili etničke/[sup]kulturalne, koje obično nisu sociopatološke, a ponekad deluju i krajnje simpatično, ali obično indukuju strepnje i bojazni domorodaca), pa najčešće ni međunarodni migranti, nisu izvor objektivne nebezbednosti, ali, zbog neželjenog prisvajanja/osvajanja prostora i nestandardnog ponašanja (koje se opaža kao uznemiravanje ili ometanje), mogu izazivati nesigurnost lokalnih stanovnika (preseljenja, čak i na manje rastojanje, potencijalno donose tenzije između društvenih grupa, a, uopšte uzev, migracije i pokretljivost stanovništva u načelu umanjuju bezbednost). Naravno, ovo pokreće i šire dileme vezane za „prava na prostor“, tj. legitimna očekivanja autohtonog stanovništva i legalnosti nastupa doseljenikâ, npr. u slučaju postepene „džentrifikacije“ i drugih socijalnoekoloških procesa; međutim, u pravne, ekonomske, socio-psihološke i druge ravni te tematike ovde se ne može upuštati.

Dakle, i za fizičke i za humane aspekte bezbednosti na određenoj teritoriji ili u izvesnom kraju grada, pored „tvrdih“ tehničkih i ekonomskih pokazatelja/svojstava, nezaobilazni su, na strani lokalnih meštana (i svih ostalih ,stejkholdera“), osećaji uzajamne sapripadnosti s prostorom, zainteresovanosti, involvisano- 
sti/uključenosti, simboličkog značaja svakog krajička površine (onaj kutak prema kojem se ne uspostavlja ili ne gaji nikakva relacija nužno zamire, te na duži rok postaje izvorište nebezbednosti). Simbolička obeležja se (kao što su ukazivali naši poznati teoretičari Ognjen Čaldarović i Ljubinko Pušić) mogu procenjivati prema gustini i intenzitetu simbolâ, što preporučuje simboličko obogaćivanje i oplemenjivanje, pa i karnevalizaciju gradskih mikrocelina. U tom smislu, ne bi trebalo potcenjivati značaj tehnološki zastarelog industrijskog i saobraćajnog (uopšte, infrastrukturnog) nasleđa - paleoindustrijskih objekata, poput vetrenjača, vodotoranja, železničkih stanica, koloseka, pa i rampi, napuštenih mostova itd, koji i danas služe kao orijentiri, simboli, toposi.

\section{Zaključna razmatranja i preporuke}

U završnim opaskama najpre valja (na normativnom nivou) odbaciti (ili makar osporiti) uskogrudi fizičko-arhitektonski/urbanistički determinizam (oblikovanje prostornih celina i sklopova u skladu sa bezbednosnim preporukama), ali i relativizovati smisao tek aposteriorne sanacije, koja figuriše jedino kao krajnji izlaz, kada su propuštene preventivne akcije. Ovim se ne potcenjuje ustaljeno pretvaranje napuštenih industrijskih i rezidencijalnih objekata u umetničke galerije, objekte socijalnog stanovanja, rekreativne centre itsl, nego se ističe prednost posibilističkog pristupa, upravljanja rizicima od samog nastanka, stalne (pre svega neformalne) kontrole i kontinuisanog praćenja emergentnih procesa. (Urbanističkoarhitektonska) struktura bez očuvanja i unapređivanja funkcije ne doprinosi bitno bezbednosti, jer su u današnje, postmoderno vreme nepredskazivi trendovi posećivanja i napuštanja konkretnih tačaka, linija i površina (kao što pokazuju primeri tržnih centara sa životnim vekom od deceniju-dve).

Mora se imati u vidu da urbana patologija ima (kako je nagoveštavao još Ziml) i svoje autogene uzroke i mehanizme, pa ne treba preuveličavati značaj fizičko-prostornih rešenja u prevenciji kriminaliteta i drugih nepoželjnih fenomena ili pak poboljšavanju opšte klime $u$ određenom ambijentu. U negativnom smislu, tj. kada su na nivou fizičkog planiranja objekti neprikladni, oni sigurno podstiču patogene oblike ponašanja (negativni posibilizam: kada se stvori ili ostavi prostor za neželjene pojave, one će se pre ispoljiti tu nego tamo gde nema tehničkih mogućnosti); no, ni najplauzibilnije arhitektonske projekcije ne mogu, same po sebi, bez aktivnog sudelovanja društvenih faktora, osujetiti zagađenje, propadanje, urbani kriminalitet i druge štetne pojave.

Utoliko se mora nedvosmisleno odrediti raspodela nadležnosti i odgovornosti između državnog nivoa, lokalne samouprave (bolje reći: zajednice/susedstva) i direktnih aktera/stejkholdera, uz njihovu blisku koordinaciju i tesnu saradnju. To za sobom povlači i izvesnu relativizaciju svojine, odnosno prava na neograničeno raspolaganje, pogotovo kad je reč o elementima koji utiču na okolne parcele i subjekte (što podrazumeva i nametanje neopozivih obaveza formalnim posednicima). Vlasništvo (u gradu) ne sme biti neprikosnoveno, jer direktno dotiče druge 
aktere, a privatnost poseda se mora tumačiti i kao dužnost da se stara o njegovom održavanju (što u vangradskim područjima nije presudno, jer ne pričinjava posebne nevolje). Nekada su mešoviti javno-privatni prostori (i lagani, kontinuisani prelazi od javnih do privatnih površina, rasprostranjeni i u postmodernim gradovima) delovali privlačno i poželjno, no, iskustvo je, s porastom bezbednosnih i drugih rizika, pokazalo da veću sigurnost pruža oštro razgraničenje, demarkacija koja jasno definiše odgovornost i obavezu nadzora za svaki delić gradskog zemljišta. GIS uliva nadu da će se za svaku pojedinačnu parcelu identifikovati (a) vlasnik, (b) sadašnji ili trajni korisnik i (v) trenutna i buduća namena, uz podatke i prognoze o predvidivim tendencijama, što čini osnov za uobličavanje „kataloga lokacijâ“, uz striktne odredbe i obaveze. Pri tome je neophodna i procena s aspekta uticaja na okruženje, zasnovana na učenju iz ranijih iskustava, kako povoljnih, tako i neželjenih.

Nasuprot arhitektonsko-urbanističkom determinizmu, neophodna je posibilistička specifičnost dizajna za različite sredine radi prevencije, međutim, u skladu sa svojom pretežnom orijentacijom (urbana sociologija), smatram presudnijim društvene činioce i procese, kao što su: društvena kohezija, (po)vezanost, participacija, inkluzija svih referentnih grupacija, blagostanje na mikronivou (ukupan kvalitet života), lokalna kultura zajednice, razumevanje i tumačenje mikrorelacija među društvenim grupama u prostoru, upotpunjene estetskim/pejzažnim dimenzijama doživljaja prostora kao sopstvenog, čak njegovom interiorizacijom kao integralnog dela ličnog subjektiviteta. Već je istaknut značaj diversifikacije aktivnosti i izbegavanja monofunkcionalnosti, omiljene u oblikovanju modernih gradova. Ali, savremeni tehnološko-proizvodni procesi iziskuju sve manje prostora i, ako su podesno osmišljeni, takođe sve manje drugih resursa (energije, žive radne snage itd) - zato se prostor danas dâ organizovati daleko ekonomičnije nego što je to moglo u ranijim epohama (pa i pre svega nekoliko decenija), tako da štednja „grinfild“-prostora (i drugih prirodnih resursa) za buduće generacije postaje imperativ sadašnje namene površina (da li će oni osećati isto što i mi, kako kaže starostavna pesma). Čuvanje grinfilda (ukupnih zemljišnih resursa) za (nepredskazive) potrebe narednih naraštaja podrazumeva ne samo restriktivno posezanje za neizgrađenim površinama unutar i izvan (gradskog) građevinskog područja, nego i ravnomerno popunjavanje građevinskog područja, ali i makar privremeno privođenje nameni (zelenilo, parkinzi, montažni objekti), samo da bi se izbeglo prepuštanje stihiji. Jednom izgrađeno zemljište, pogotovo današnjim masivnim zdanjima ili infrastrukturnim objektima, postaje praktično neupotrebljivo (ili vrlo ograničeno iskoristivo) za druge namene.

Stoga se već i prilikom urbanističko-arhitektonskog planiranja moraju uzimati u obzir predviđene ili naslućene buduće (pre)namene i eventualne promene u pravcima razvoja, a, koliko god je to moguće, valja favorizovati multifunkcionalnost i izlaženje ususret potrebama i željama što većeg broja subjekata tokom što više vremena. Nije poenta u dodatnom razvijanju teorijskih ideja o revitalizaciji (kakva su poodavno razrađena u svrhu urbane rekonstrukcije ili obnove), nego u njihovoj implementaciji u opštem/javnom interesu. 


\section{Literatura}

1. Bobić, Đorđe, 2009, „Traganje za gradom - urbana reciklaža ... to je razumno“, http://djordjebobic.com/?p=603, pristupljeno 21. 4. 2017.

2. Bojović, Miodrag Todorov, 1997, Urbana ekologija, Književna trajna radna zajednica Zenit, Beograd.

3. Brownfield investicione lokacije - ekoremedijacioni modeli i ekonomska valorizacija, 2017, Zbornik radova - Nacionalna konferencija sa medunarodnim učešcem, Fakultet za primenjenu ekologiju Futura, Beograd.

4. Vasić, Vladimir, 2016, „Braunfid u tržišnom sivilu“, Mašina. Proizvodnja društvene kritike, 19. 7., http://www.masina.rs/?p=3084, pristupljeno 21. 4. 2017.

5. Gligorijević, Žaklina, 2007, „Urbana reciklaža, strategija za revitalizaciju urbanog i istorijskog nasleđa gradova“, INFO 2007, god. V, br. 18, Specijalno izdanje: Staro beogradsko sajmište, Urbanistički zavod Grada Beograda, str. 25-39.

6. Ecological improvement of devastated locations for sustainable development, 2014, International Conference, Conference Proceedings, ed. Gordana Dražić, Faculty of Applied Ecology Futura, Singidunum University, September $29^{\text {th }}$ and $30^{\text {th }}$.

7. Jovanović, Tamara, 2010, Prazni prostori Srbije. Prva faza projekta - Beograd, Zavod za proučavanje kulturnog razvitka, Beograd.

8. Kostić, Cvetko, 1982, Grad i vreme. Osnovi sociologije grada, „Vuk Karadžić“, Beograd.

9. Lješević, Milutin A., 2009, Urbana ekologija. Nauka o životnoj sredini 2, Univerzitet Singidunum, Fakultet za primenjenu ekologiju Futura i NVO Ekorizik, Beograd.

10. Minić, Marta, i Ana Perić, 2016, „Regeneracija braunfild lokacija: ka jačanju socijalne kohezije?", Arhitektura i urbanizam, br. 42, str. 41-47.

11. Oživljavanje braunfilda u Srbiji, 2008, Priručnik za donosioce odluka i profesionalce, PALGO centar i Stalna konferencija gradova i opština, Beograd.

12. Pušić, Ljubinko, 1991, Grad: znaci vremena, Matica srpska, Novi Sad.

13. Reaktiviranje braunfilda $u$ Srbiji. Sistematski pristup ili ad hoc rešenja, 2011, Stalna konferencija gradova i opština, Beograd.

14. Smrečnik, Tomislav, Boris Kordić i dr., 2006, Procena održivosti razvoja kvaliteta lokalne zajednice. Metodološka matrica dimenzija, aspekata, podaspekata i parametara, Fakultet civilne odbrane, Beograd.

15. Stojkov, Borislav, 2007, „Ka recikliranju građevinskog zemljišta u Srbiji“, Glasnik Srpskog geografskog društva, sv. LXXXVII, br. 2, str. 175-185.

16. Todorović, Aleksandar, 1965, Uvod u sociologiju grada, „Vuk Karadžić“", Beograd.

17. Ćirić, Jovan, 2011, „Pogled u tuđe dvorište kroz 'polomljeni prozor'“, Strani pravni život, god. 56, br. 1, str. 11-28.

18. Filipović, Dejan, 2012, „Planska dokumentacija kao osnova sistema upravljanja otpadom“, u: Problemi i izazovi savremene geografske nauke i nastave. Međunarodni naučni skup, Univerzitet u Beogradu - Geografski fakultet, Beograd, str. 521-526.

19. Čaldarović, Ognjen, 1987, Suvremeno društvo $i$ urbanizacija, Školska knjiga, Zagreb. 


\title{
INSECURITAS VACUI. Dangers Resulting from Deserted Urban Locations
}

\begin{abstract}
Summary
Leaving aside national security aspects of huge wasteland in rural areas, which have grown ever stronger recently, the presentation will focus on the dangers that loom over neglected or abandoned microlocations. They, as places of ruined buildings and habitats of insects and rodentia, and of historical contamination of soil and air (deposits or piles of buildings, industrial and communal waste) pose not only physical-technical and ecological threat to the environment, but are, at the same time, the meeting place of various marginal or deviant groups, and a potential source of (spread of) criminal and social pathology. In other words, this contribution will explain physical-ecological as well as social-ecological effects of urban blight. First of all, the paper will elucidate the root causes for the appearance of such locations, i.e.why they have been abandoned or neglected. These causes do not lie exclusively in the domain of economy, but also comprise architectural-urban and social environment. Consequently, it is necessary, for the sanitation or regulation of those (un)places, to undertake all-embracing measures at various levels of action. Albeit the contribution will consider very urgent topics of brownfield as a heritage of modernity and an aftermath of the global resettlement of industrial and other contents, too (not attempting their detailed classification), the emphasis will be put on narrower locations (vacant building plots, unfinished or temporarily abandoned objects, poorly visited quarters of public areas). These are micro-zones that are, due to a lack in care or social surveillance, designated as potential focus-points of future problems (the so-called syndrome of broken window), no matter whether it concerns private or public space (or any transitory form). While those locations exist in rural settlements, too, there they do not induce such a threat, since population density is lowerand the level of social control higher. Suggesting a model of recuperation of blight zones, the paper will start from the concept of responsibility of occupants/owners of real estates, local community/administration and the society/state as a whole, with clearly defined duties of all the subjects/stakeholders (and institutional imposition of employment conditions). That would mean fixed-term obligation, compulsory definition of its use (and desirably multiple, for mono-functioning is a negative capacity for generating a vacuous space or negative niches) and stimulating complete and multifarious use of each item of an urban area, as a rare and precious, but also a risky resource. Thereby, the contribution will not regard only a short-time, narrow economic interests (which is widespread in literature on brownfields), but primarily a vision of sustainable development at a macro-level that does not encourage the orientation towards expansion/invasion to greenfields at the town outskirts. In order to provide predictability (for the sake of prevention and timely reaction), the text delineates a set of indicators of blight/deterioration/abandonment, whose values should serve as markers of caution, when costs of revitalization are lower, and social merit or usefulness is greater.
\end{abstract}

Keywords: abandoned places, brownfield, urban ecology, sanitation, revitalization, local community 